\title{
IMOBILIZAÇÃO DE INULINASE COMERCIAL EM NANOTUBOS DE CARBONO FUNCIONALIZADOS
}

\author{
T. B. GARLET ${ }^{1}$, C. T. WEBER ${ }^{1}$, E. L. FOLETTO ${ }^{1}$, S. L. JAHN ${ }^{1}$, M. A. MAZUTTI ${ }^{1}$, R. C. \\ $\mathrm{KUHN}^{1}$ \\ ${ }^{1}$ Universidade Federal de Santa Maria, Departamento de Engenharia Química \\ E-mail para contato: raquelckuhn@yahoo.com.br
}

\begin{abstract}
RESUMO - O presente trabalho teve como objetivo principal definir uma estratégia para a imobilização de inulinase comercial em nanotubos de carbono funcionalizados. No delineamento composto central rotacional (DCCR) a concentração de enzima $(0,87 \%$ e $1,72 \%$ (v/v)) e a razão adsorvente:adsorbato (1:175 e 1:460) foram as variáveis independentes. As cinéticas foram mantidas até equilíbrio, sendo este atingido aos seis minutos em todos os ensaios. De acordo com os resultados do DCCR a variável concentração de enzima apresentou um efeito negativo sobre a imobilização da inulinase, a razão adsorvente:adsorbato e a interação entre as duas variáveis apresentaram efeitos positivos $(p<0,10)$. A enzima imobilizada manteve praticamente $100 \%$ da atividade relativa a $50{ }^{0} \mathrm{C}$ durante 240 minutos. Portanto, os nanotubos avaliados são considerados adsorventes promissores, devido ao rápido equilíbrio de adsorção, sendo assim definida uma estratégia de imobilização de enzimas.
\end{abstract}

\section{INTRODUÇÃO}

A imobilização consiste no confinamento da enzima em um suporte sólido para posterior reutilização do biocatalisador, é vantajosa para aplicação industrial devido a facilidade de separação do meio de reação e o reutilização da mesma, o baixo custo do produto e a possibilidade de aumento da estabilidade (Husain, 2010).

As inulinases são enzimas potencialmente utilizadas na produção de xaropes de frutose pela hidrólise enzimática da inulina com rendimentos de até 95\% (Ettalibi e Baratti, 2001). Também possuem aplicação na produção de frutooligossacarídeos, compostos com propriedades funcionais e nutricionais com aplicação em dietas de baixas calorias, estimulação das bactérias benéficas do organismo, funcionando como fibras dietéticas quando aplicada aos alimentos (Silva- Santisteban e Maugeri, 2005).

Nanomateriais podem servir como um eficiente suporte para imobilização de enzimas, pois oferecem características ideais que são determinantes na eficiência do biocatalisador, incluindo a superfície de área e a resistência a transferência de massa. Os nanomateriais têm sido extensivamente utilizados para imobilização de enzimas, neste caso, as nanopartículas podem proporcionar uma maior superfície de área para as enzimas, o que conduz a uma maior quantidade de enzima por quantidade de massa de partícula (Ji et al., 2010). 
Entre os vários materiais utilizados como nanoestruturas, estão as nanopartículas, nanofibras e nanotubos, os nanotubos de carbono (CNTs) têm sido foco de muitas pesquisas (Feng e Ji, 2011). Os CNTs são compostos de grafite em forma de cilindro com comprimentos de micrômetros, e diâmetros de até $100 \mathrm{~nm}$ (Tasis et al., 2006). Apresentam uma afinidade natural por diversos tipos de enzima, onde a adsorção é espontânea quando a enzima entra em contato com este material (Feng e Ji, 2011). Os nanotubos de carbono podem promover a imobilização de uma enzima específica, sendo o principal desafio promover a fixação da enzima, mantendo sua atividade e função mais próximas de seu estado nativo (Pedrosa et al., 2010). As vantagens dos métodos de imobilização de enzimas por adsorção neste material são claros, dentre eles a manutenção da estrutura da proteína e as propriedades dos CNTs. Entretanto, a durabilidade é uma preocupação da aplicação dos métodos de adsorção, visto que a ligação covalente das enzimas pode resultar em alta estabilidade e reuso da enzima (Feng e Ji, 2011).

Em vista do que foi exposto, o objetivo deste trabalho foi definir uma estratégia de imobilização da inulinase em nanotubos de carbono funcionalizados, para isto foram estudadas as variáveis que influenciaram na imobilização da inulinase, dentre elas, a concentração de enzima e a razão adsorvente:adsorbato através de metodologia de planejamento experimental. Na melhor condição de imobilização foi avaliada a estabilidade a diferentes temperaturas.

\section{MATERIAL E MÉTODOS}

\subsection{MATERIAL}

A inulinase comercial foi adquirida da Sigma-Aldrich obtida de Aspergillus niger. Os nanotubos de carbono funcionalizados $(\mathrm{CNT}-\mathrm{COOH})$ foram adquiridos da NanoAmor (EUA) sendo utilizados como adsorvente. Os demais reagentes utilizados foram de grau analítico.

\subsection{ENSAIOS DE ADSORÇÃO}

Foram realizadas cinéticas de adsorção da solução de inulinase com os nanotubos de carbono funcionalizados. Sendo pesados em erlenmeyers $0,025 \mathrm{~g}$ de nanotubos de carbono sendo adicionado solução de inulinase em tampão acetato $0,1 \mathrm{M}(\mathrm{pH} 4,8)$ conforme delineamento composto central rotacional (Tabela 1). As cinéticas foram realizadas em agitador rotativo (shaker) a $25{ }^{0} \mathrm{C}$ até o equilíbrio. A capacidade de adsorção da solução de inulinase $\left(\mathrm{Q}_{\mathrm{t}}\right)$ no nanotubo de carbono no tempo $(\mathrm{t})$ foi calculada de acordo com a Equação 1.

$Q_{t}=\frac{\left(A_{0}-A_{t}\right) V}{m}$

onde $A_{0}(\mathrm{U} / \mathrm{mL})$ é a atividade inicial da solução de inulinase, $A_{t}(U / m L)$ é a atividade da solução no tempo t, V (mL) é o volume da solução de inulinase, e m (g) é a massa de nanotubo de carbono.

\subsection{DELINEAMENTO COMPOSTO CENTRAL ROTACIONAL}

Para avaliação das cinéticas de adsorção foi delineado um planejamento experimental completo (DCCR) com três pontos centrais, onde as variáveis independentes foram a concentração de enzima e a razão adsorvente:adsorbato, conforme descrito na Tabela 1. 
Tabela 1 - Variáveis reais e codificadas do delineamento composto central rotacional (DCCR)

\begin{tabular}{|c|c|c|c|c|c|}
\hline & $-1,41$ & -1 & 0 & +1 & $+1,41$ \\
\hline Concentração enzima (\%) & 0,87 & 1 & 1,3 & 1,6 & 1,7 \\
\hline Razão adsorvente:adsorbato & $1: 175$ & $1: 200$ & $1: 300$ & $1: 400$ & $1: 460$ \\
\hline
\end{tabular}

\subsection{TERMOESTABILIDADE DA ENZIMA}

Os ensaios avaliando a termoestabilidade da enzima foram realizados na melhor condição definida no DCCR. A termoestabilidade da enzima imobilizada foi determinada a diferentes temperaturas $\left(30,50\right.$ e $\left.70{ }^{\circ} \mathrm{C}\right)$ durante 240 minutos. A atividade da enzima foi avaliada a cada 30 minutos sendo definida como atividade relativa em relação a atividade inicial.

\subsection{DETERMINAÇÃO DA ATIVIDADE ENZIMÁTICA}

A atividade de enzima foi medida através da incubação de $0,5 \mathrm{~mL}$ da enzima apropriadamente diluída em 4,5 mL de sacarose (2\% p/v) em tampão acetato $(0,1 \mathrm{M} \mathrm{pH} \mathrm{4,8)} \mathrm{a}$ $50^{0} \mathrm{C}$. Os açúcares redutores foram quantificados através do método 3,5-DNS (Miller, 1959). Uma unidade de enzima foi definida como a quantidade de enzima necessária para liberar 1 $\mu$ mol de açúcares redutores por minuto em condições padrão.

\section{RESULTADOS E DISCUSSÃO}

As cinéticas de adsorção foram realizadas até atingirem o equilíbrio da reação, na Tabela 2 estão apresentados os resultados para capacidade de adsorção, obtidos aos seis minutos de reação onde todas as condições avaliadas haviam atingido o equilíbrio, sendo este o tempo considerado para imobilização da inulinase.

Tabela 2 - Valores codificados e reais (entre parênteses) para as variáveis do DCCR e resultados da inulinase imobilizada

\begin{tabular}{|c|c|c|c|}
\hline Ensaios & $\begin{array}{c}\text { Concentração } \\
\text { enzima (\%) }\end{array}$ & $\begin{array}{c}\text { Razão } \\
\text { adsorvente:adsorbato }\end{array}$ & $\begin{array}{c}\text { Imobilização } \\
(\mathrm{U} / \mathrm{g})\end{array}$ \\
\hline 1 & $-1(1)$ & $-1(1: 200)$ & 49570,90 \\
\hline 2 & $1(1,6)$ & $-1(1: 200)$ & 26665,60 \\
\hline 3 & $-1(1)$ & $1(1: 400)$ & 45774,44 \\
\hline 4 & $1(1,6)$ & $1(1: 400)$ & 45286,32 \\
\hline 5 & $-1,41(0,87)$ & $0(1: 300)$ & 39331,28 \\
\hline 6 & $1,41(1,7)$ & $0(1: 300)$ & 30784,64 \\
\hline 7 & $0(1,3)$ & $-1,41(1: 175)$ & 24603,97 \\
\hline 8 & $0(1,3)$ & $1,41(1: 460)$ & 51047,76 \\
\hline 9 & $0(1,3)$ & $0(1: 300)$ & 38715,53 \\
\hline 10 & $0(1,3)$ & $0(1: 300)$ & 40217,43 \\
\hline 11 & $0(1,3)$ & $0(1: 300)$ & 40175,71 \\
\hline
\end{tabular}


Através dos resultados obtidos na Tabela 2, foram avaliados os efeitos das variáveis estudadas, onde através da Figura 1, são observados que a concentração de enzima teve um efeito negativo sobre a resposta e as variáveis razão adsorvente:adsorbato e a interação entre as duas variáveis tiveram efeitos positivos $(\mathrm{p}<0,10)$. Ou seja, com o aumento da concentração de enzima menor a capacidade de adsorção da enzima no material, o contrário é observado em relação a razão adsorvente:adsorbato quanto maior a razão melhor a capacidade de adsorção da enzima.

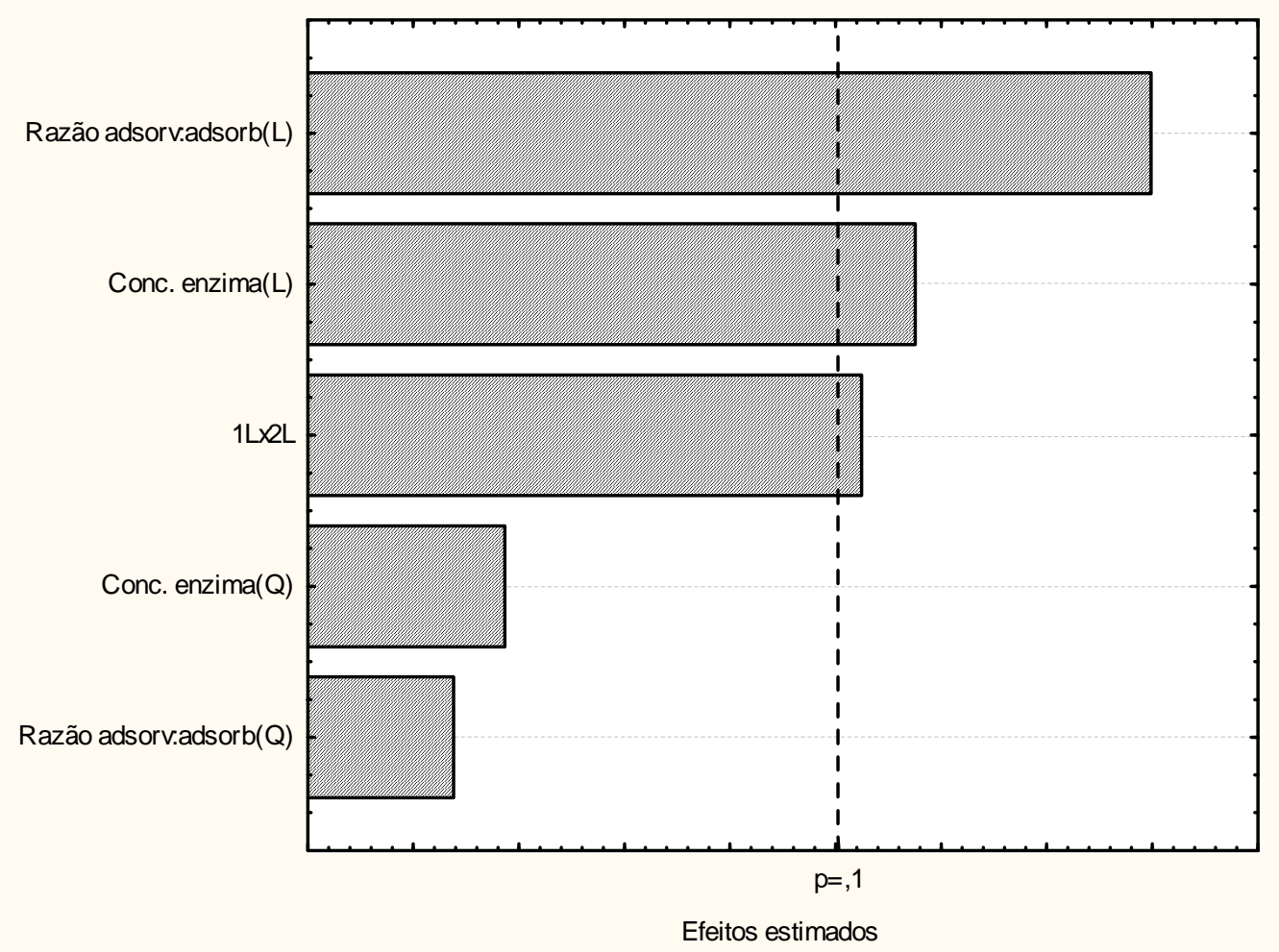

Figura 1 - Efeitos estimados para as variáveis avaliadas na imobilização da inulinase.

Os efeitos foram relacionados aos termos de um modelo quadrático apresentado na Eq. 2. A Eq. 2 apresenta os termos significativos $(p<0,10)$ em relação a capacidade de adsorção da inulinase.

Adsorção $(\mathrm{U} / \mathrm{g})=39681,47$ - 8887,48.E + 13066,38.R + 11208,59. E.R

Onde $\mathrm{E}=$ concentração de enzima $(\%) ; \mathrm{R}=$ razão adsorvente:adsorbato.

O modelo apresentado foi estatisticamente validado pela análise de variância (ANOVA) (Tabela 3). $\mathrm{O}$ valor do $\mathrm{F}_{\text {calculado }}$ foi três vezes superior ao valor tabelado e o modelo apresentou um coeficiente de regressão $\left(\mathrm{r}^{2}\right)$ de 0,81 .

Através da curva de contorno (Figura 2) podem ser observados que as melhores respostas foram obtidas nas menores razões de adsorvente:adsorbato e concentração de enzima, condições estudadas no ensaio 1, e também nas maiores concentrações adsorvente:adsorbato e concentrações intermediárias de enzima, ensaio 8. 
Tabela 3 - Análise de variância (ANOVA)

\begin{tabular}{|c|c|c|c|c|}
\hline & $\begin{array}{c}\text { Soma dos } \\
\text { quadrados }\end{array}$ & $\begin{array}{c}\text { Graus de } \\
\text { liberdade }\end{array}$ & $\begin{array}{c}\text { Quadrado } \\
\text { médio }\end{array}$ & $\mathrm{F}_{\text {calculado }}$ \\
\hline Regressão & 623581895 & 3 & 207860631,7 & 9,848797 \\
\hline Resíduos & 147736259 & 7 & 21105179,92 & \\
\hline Total & 771318154 & 10 & & \\
\hline
\end{tabular}

$\mathrm{F}_{3 ; 7 ; 0,1}=3,07$

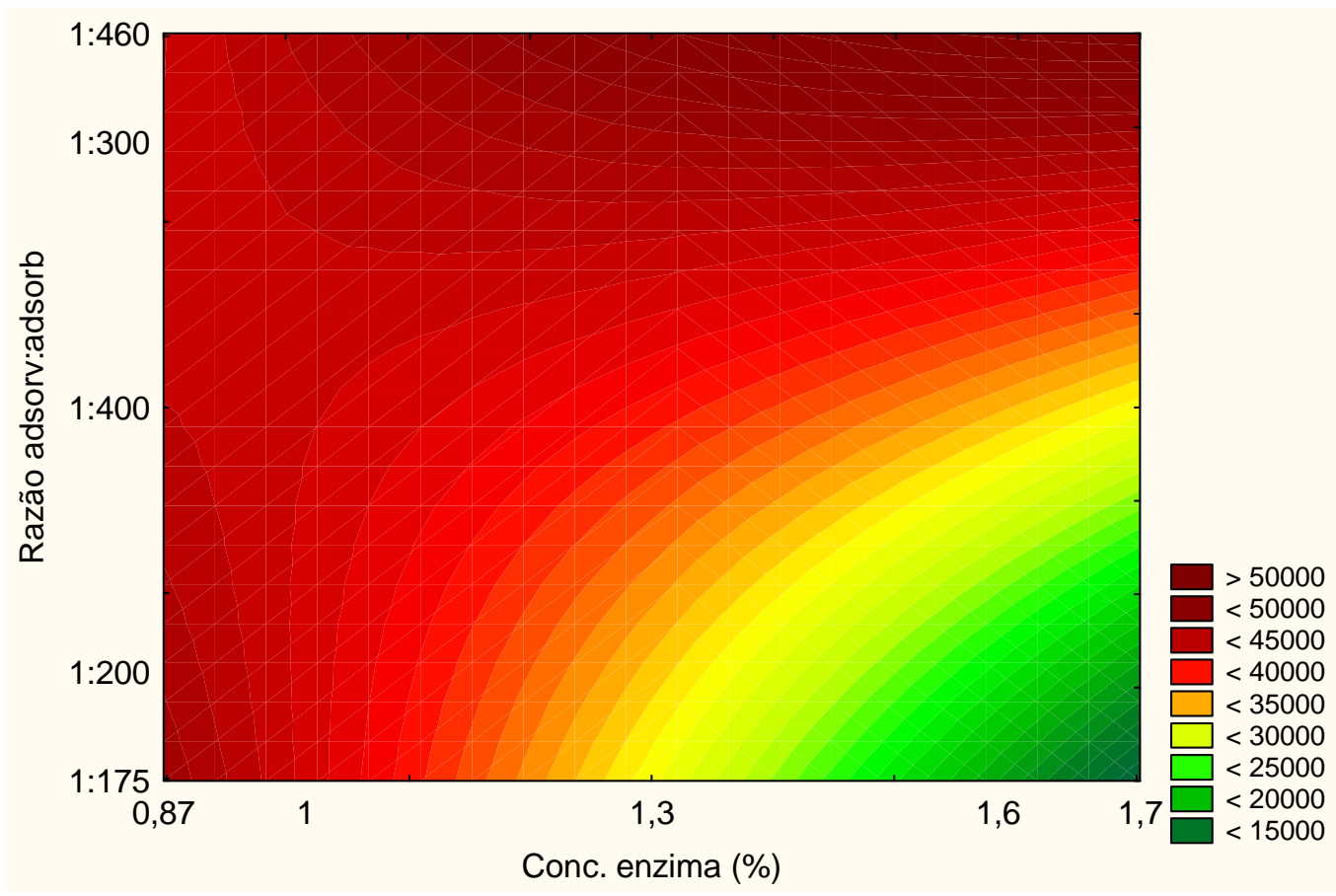

Figura 2- Curva de contorno para a resposta capacidade de imobilização da enzima.

Na melhor condição do planejamento experimental, a termoestabilidade da enzima foi avaliada em diferentes temperaturas, dados apresentados na Figura 3, onde podem ser observados que a $50{ }^{0} \mathrm{C}$ a enzima manteve sua atividade inicial por aproximadamente 240 minutos, o mesmo não foi observado para as temperaturas de 30 e $70{ }^{\circ} \mathrm{C}$, onde após 240 minutos a atividade relativa da enzima era cerca de 45 e $47 \%$, respectivamente. Resultados semelhantes para a melhor temperatura foram encontrados por outros autores, Yewale et al. (2013); Danial et al. (2010) estudaram diferentes temperaturas na estabilidade da inulinase imobilizada e encontraram a temperatura de $60{ }^{0} \mathrm{C}$ como a que manteve quase $100 \%$ da atividade relativa durante 120 minutos de reação. 


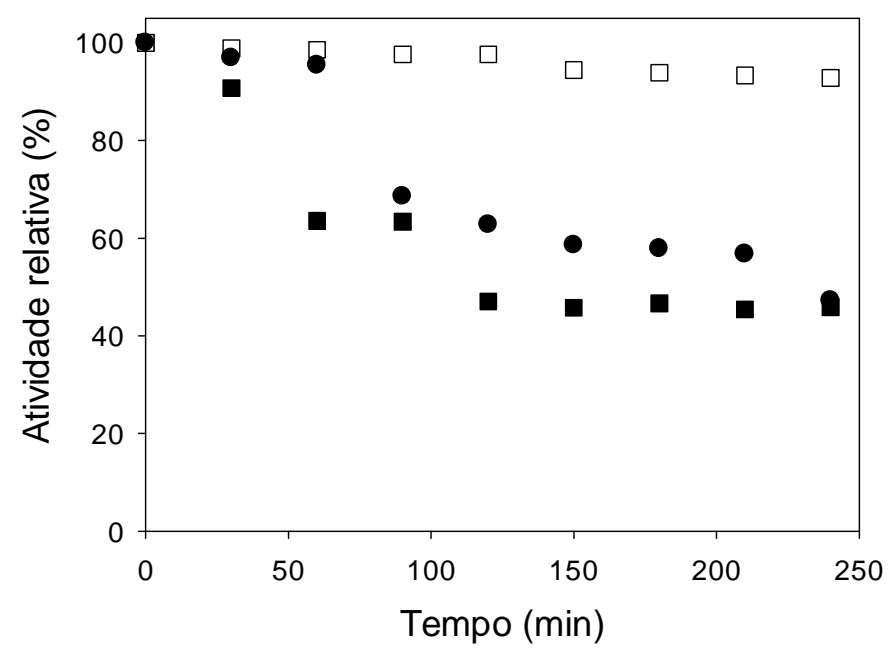

Figura 3 - Termoestabilidade da inulinase $\left((\bullet) 30{ }^{\circ} \mathrm{C},(\square) 50{ }^{0} \mathrm{C}\right.$ e $\left.(\bullet) 70{ }^{0} \mathrm{C}\right)$.

\section{CONCLUSÃO}

No presente trabalho foram definidas as melhores condições para a imobilização de inulinase comercial em nanotubos de carbono funcionalizados através de metodologia de planejamento experimental. Através da curva de contorno do planejamento experimental foram definidas as melhores condições para a adsorção da enzima, sendo nas menores concentrações de enzima e maiores razões de adsorvente:adsorbato. A enzima manteve praticamente $100 \%$ de sua atividade relativa a $50{ }^{\circ} \mathrm{C}$ durante 240 minutos, sendo esta a melhor condição para processos envolvendo a enzima imobilizada dentre as temperaturas estudadas. Com os resultados foi possível definir uma metodologia para imobilização de inulinase em nanotubos com potencial para aplicação em larga escala.

\section{REFERÊNCIAS}

DANIAL, E. N.; ELNASHAR, M. M. M.; AWAD, G. E. A. Immobilized inulinase on grafted alginate beads prepared by the one-step and the two-steps methods. Ind. Eng. Chem. Res., v. 49, p. 3120-3125, 2010.

ETTALIBI, M.; BARATTI, J. C. Sucrose hydrolysis by thermostable immobilized inulinases from Aspergillus ficcum. Enzyme Microbioly Technol, v. 28, p. 596-601, 2001.

FENG, W.; J.I., P. Enzymes immobilized on carbon nanotubes. Biotechnol Advances, v. 29, p. 889-895, 2011.

HUSAIN, Q. $\beta$. Galactosidase and their potential applications. Critical Rev Biotechnol, v. 30, p. 41-62, 2010. 
JI, P., TAN, H., XU, X., FENG, W. Lipase covalently attached to multi-walled carbon nanotubes as an efficient catalyst in organic solvent. AIChE J, v. 56, p. 3005-11, 2010.

MILLER, G. L. Use of dinitrosalisylic acid reagent for determination of reducing sugar. Analytical Chem, v. 31, p. 426-428, 1959.

PEDROSA, V.A.; PALIWAL, S.; BALASUBRAMANIAN, S.; NEPAL, D.; DAVIS, V.; WILD, J.; RAMANCULO, E.; SIMONIAN, A. Enhanced stability of enzyme organophosphate hydrolase interfaced on the carbon nanotubes. Colloids and Surfaces B: Biointerfaces, v. 77, p. 69-74, 2010.

SILVA, B.O.Y.; MAUGERI, F. Agitation, aeration and shear stress as key factors in inulinase production by Kluyveromyces marxianus. Enzyme Microbioly Technol, v. 36, p. 717-724, 2005.

TASIS, D.; TAGMATARCHIS, N.; BIANCO, A.; PRATO, M. Chemistry of carbon nanotubes. Chem Ver, v. 106, p. 1105-36, 2006.

YEWALE, T.; SINGHAL, R. S.; VAIDJA, A. A. Immobilization of inulinase from Aspergillus niger NCIM 945 on chitosan and its application in continuous inulin hydrolysis. Biocatal and Agric Biotech, 2: 96-101, 2013. 